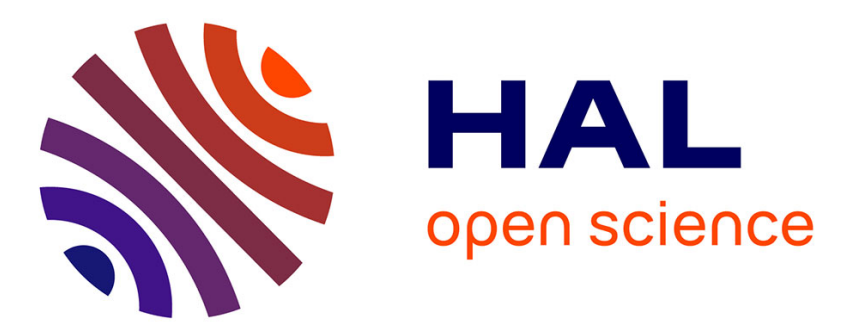

\title{
Evaluating the Effects of Tidal Turbines on Water-Mass Transport with the Lagrangian Barycentric Method
}

\author{
Nicolas Guillou, G. Chapalain
}

\section{To cite this version:}

Nicolas Guillou, G. Chapalain. Evaluating the Effects of Tidal Turbines on Water-Mass Transport with the Lagrangian Barycentric Method. 6th International Conference on Estuaries and Coasts, Aug 2018, Caen, France. hal-01865267

\section{HAL Id: hal-01865267 https://hal.science/hal-01865267}

Submitted on 25 Sep 2018

HAL is a multi-disciplinary open access archive for the deposit and dissemination of scientific research documents, whether they are published or not. The documents may come from teaching and research institutions in France or abroad, or from public or private research centers.
L'archive ouverte pluridisciplinaire HAL, est destinée au dépôt et à la diffusion de documents scientifiques de niveau recherche, publiés ou non, émanant des établissements d'enseignement et de recherche français ou étrangers, des laboratoires publics ou privés. 


\title{
Evaluating the Effects of Tidal Turbines on Water-Mass Transport with the Lagrangian Barycentric Method
}

\author{
Guillou Nicolas*, Chapalain Georges \\ Cerema, DtecEMF, ER, Laboratoire de Génie Côtier et Environnement, \\ 155 rue Pierre Bouguer, Technopôle Brest-Iroise, BP 5, 29280 Plouzané, France
}

\begin{abstract}
Characterising circulation pathways in tidal stream energy sites is fundamental to evaluate the effects of turbines power extraction on long-term water-mass transport. The Lagrangian residual currents are commonly used to assess the displacement of water particles over the tidal period. The associated circulation is, however, characterised by a strong dispersion as water particles may follow different trajectories depending on the release time during a tidal cycle. In order to obtain a synthetic cartography of the Lagrangian circulation, Salomon et al. (1988) proposed an original method that allocates the residual currents at the barycentre of particle trajectories. This Lagrangian barycentric method was here applied to the Fromveur Strait (western Brittany) - a region with strong potential for turbine farm implementation along the coast of France. A high-resolution depth-averaged numerical model computed the tidal circulation driven by the principal lunar semi-diurnal constituent $\mathrm{M}_{2}$. The initial particle positions were taken at the 14,026 nodes of the unstructured computational grid surrounding the area of interest with a spatial resolution below 50 $\mathrm{m}$. In the strait, the residual Lagrangian circulation was characterised by a strong asymmetry between (i) a prominent north-eastern pathway with residual currents up to $0.45 \mathrm{~ms}^{-1}$ and (ii) a southward circulation. Both upstream and downstream the strait, we exhibited prominent cyclonic and anti-cyclonic recirculations. A close correlation was found between the north eddy and a prominent sand bank. We simulated the forces induced by a series of horizontal-axis turbines as an additional bed friction sink term at the scale of the tidal farm. The extraction of tidal stream energy modified the amplitude and direction of the Lagrangian circulation along the current stream emerging from the strait with (i) a tendency for surrounding eddies to get closer to the tidal stream energy site and (ii) possible effects on the evolution of surrounding seabed features.
\end{abstract}

Key words: Tidal Flow Asymmetry; Water Particles; Drifters; Numerical Modelling; Telemac; Fromveur Strait.

\section{Introduction}

The evaluation of water-mass transport in tidal stream energy sites is of great ecological interest in assessing water-quality changes induced by turbines power extraction. This includes effects on trapping and dispersion of fish eggs, larvae, nutrients, and suspended sediments (Edwards et al., 2006). But it may also serve specific objectives like transport predictions of (i) drifters potentially harmful to structures' blades or (ii) polluting substances accidentally released by devices (Sanderson and Redden, 2015). Transport studies in stream energy sites were, however, primarily dedicated to changes induced by turbines on sediment transport (e.g., Neill et al., 2012; Fairley et al., 2015; Thiébot et al., 2015). Shapiro (2011) conducted a preliminary numerical evaluation of turbines' effects on passive tracer pathways in the Celtic Sea, north of Cornwall (the United-Kingdom). Nevertheless, simulations operated a single release of floats disregarding the influence of the initial drop time on particle trajectories.

In this study, we investigated the impacts of tidal stream power extraction on the long-term displacement of water particles by exhibiting changes induced on the Lagrangian Residual Circulation (LRC). As water particles may follow different trajectories depending on the release time during a tidal cycle, residual currents are characterised by a strong dispersion and are difficult to define in a single synoptic view. We thus relied on an original method, proposed by Salomon et al. (1988), to map the LRC in the English Channel and western Brittany. This technique, denominated Lagrangian barycentric, applies for a tidal circulation driven by a single tidal harmonic, such as the principal lunar semi-diurnal component $\mathrm{M}_{2}$ along the Atlantic coast of Europe. It provided furthermore a first overview of long-term transport pathways in north-western European shelf seas while significantly reducing the

\footnotetext{
**nicolas.guillou@cerema.fr
} 
computational time (Orbi and Salomon, 1988; Salomon and Breton, 1993; Breton and Salomon, 1995).

The method was applied to the Fromveur Strait, off western Brittany, which separates the island of Ushant from the Molène archipelago through a $2 \mathrm{~km}$ wide and $50 \mathrm{~m}$ deep strait (Fig. 1). This location was identified, with the Alderney Race in the English Channel, as one of the largest tidal stream energy resources along the coast of France (Guillou et al., 2018). The French government thus identified a restricted area of $4 \mathrm{~km}^{2}$ within the strait for the implementation of tidal stream arrays. A series of numerical investigations were conducted in this site to refine the predictions of available tidal kinetic energy and evaluate the short-term hydrodynamic effects induced by tidal stream power extraction (Guillou et al., 2016; Guillou and Thiébot, 2016; Guillou, 2017). Nevertheless, no modelling study was dedicated to capture of, at high-spatial resolutions $(\sim 50-100 \mathrm{~m})$, (i) the tide-induced circulation pathways in this strait and (ii) the changes associated with tidal stream power extraction.

An original approach was adopted to couple the Lagrangian barycentric method (Section 2.1) with numerical predictions of particle tracking obtained at highspatial resolution in the strait (Section 2.2). Predictions were assessed against available measurements of current amplitude and direction at two locations in the area of interest (Section 3.1). LRC patterns were interpreted in relation to the tidal-current asymmetry and recirculations in the area of interest (Section 3.2). This investigation was completed by an analysis of long-term particle trajectories (Section 3.3). Changes induced by a series of horizontalaxis turbines, varying in numbers, were finally evaluated (Section 3.4).

\section{Materials and Methods}

\subsection{Lagrangian Barycentric Method}

The different steps of the Lagrangian barycentric method are briefly detailed hereafter. Further information can be found in Salomon et al. (1988), Orbi and Salomon (1988), and Salomon and Breton (1993).

The first step is to compute, based on a particletracking numerical method, the trajectories of drifters released at hourly intervals during a tidal cycle. The circulation model is driven by a mono-frequency tide to emphasise the single period that characterises the long-term displacements of water particles. The dominant semidiurnal constituent $\mathrm{M}_{2}$ is usually retained along the European Atlantic coast. The initial particle positions have to be spread over the area of interest while covering, with a refined spatial resolution, shoals and coastal irregularities that may impact the tidal circulation.

The second step is to compute the Lagrangian residual currents defined as the displacements of water particles over the tidal period considered (Zimmerman, 1979). For a
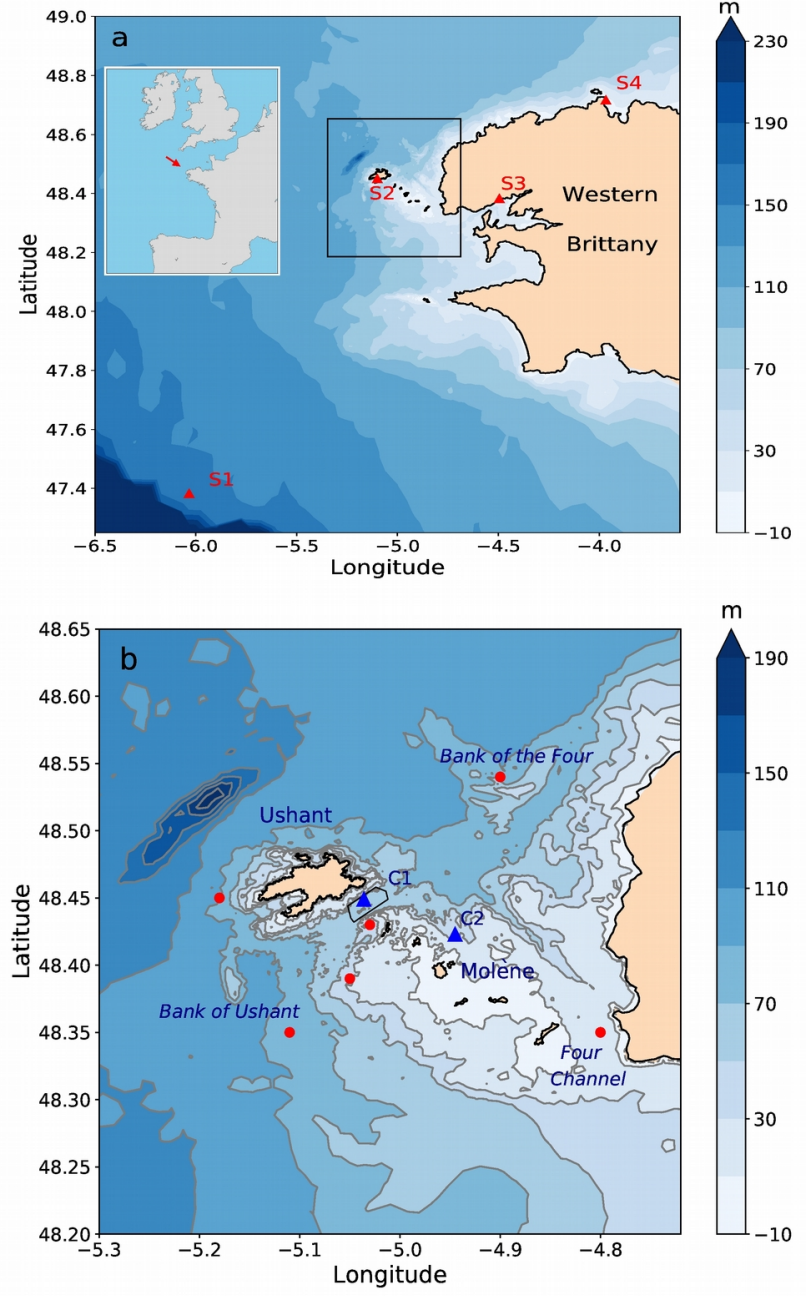

Figure 1. Bathymetry of the Ushant-Molène archipelago with locations of available tidal gauges S1-S4 (red triangles), current meters $\mathrm{C} 1$ and $\mathrm{C} 2$ (blue triangles) and initial positions of floats for assessing long-term particles trajectories (red circles). The black line delimits the area of interest for turbine implementation in the Fromveur Strait. Water depth is relative to mean sea level.

given initial position, a series of Lagrangian residual currents is thus obtained, the total number matching with the number of particles released during a tidal cycle. The computed vector field presents, however, a strong dispersion that exhibits the influence of the release time on particle trajectories (Fig. 2). At a given position, this is characterised by a beam of Lagrangian velocities that is very difficult to analyse and interpret. In order to reduce the dispersion of the vector field, residual currents are allocated at the barycentre of computed trajectories, considered to be more representative of particle displacements.

The non-divergence of the velocity field is finally evaluated. The result is a single Lagrangian residual 


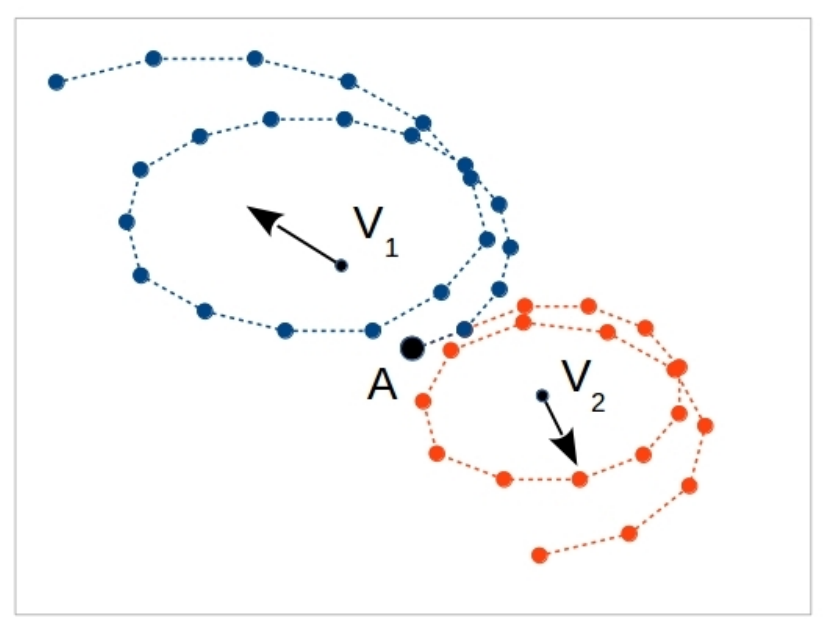

Figure 2. Schematic representation of the barycentric system.

velocity field that can be exploited to identify and depict the major patterns of tide-induced particle transport.

\subsection{Numerical Modelling}

The application of the Lagrangian barycentric method in the Fromveur Strait relied on numerical simulations of tidal currents conducted by Guillou and Thiébot (2016). The depth-averaged model Telemac 2D (version v6p3; Hervouet, 2007) was implemented on an unstructured computational grid covering the western extend of Brittany with a spatial resolution of $10 \mathrm{~km}$ at offshore sea boundaries to less than $50 \mathrm{~m}$ in the strait. Whereas the area of interest may be subjected to storm wave conditions liable to impact tidal currents (e.g., Guillou and Chapalain, 2015; Guillou et al., 2016), these effects were disregarded driving simulations with the dominant $\mathrm{M}_{2}$ component and its quarter-diurnal generated harmonic $\mathrm{M}_{4}$. Integrating the $\mathrm{M}_{4}$ forcings was found to improve its generation from $\mathrm{M}_{2}$ in the numerical model, in particular at open boundaries close to landmass (Pingree and Maddock, 1978; Guillou and Chapalain, 2010). A series of major harmonic components was furthermore considered to assess model's performances with respect to in-situ currents measurements. The harmonic components were extracted from the TPXO7atlas 2011 database that covers the area of interest with a spatial resolution of $1 / 12^{\circ}$ (Egbert and Erofeeva, 2002).

Particle trajectories were computed with the transport module of Telemac 2D (EDF R\&D, 2013; Joly et al., 2014). The initial particle positions were taken at the 14,026 nodes of the computational grid surrounding the Ushant-Molène archipelago (Fig. 3). Particles were released at a hourly interval during a $\mathrm{M}_{2}$ tidal cycle, resulting in a field of 182,338 $(=13 \times 14,026)$ Lagrangian residual vectors. The velocity field was allocated at the barycentre of particle trajectories and finally, its non-divergence was finally evaluated.
In the numerical model, the effect of tidal stream power extraction on the tidal circulation was integrated as an additional bed friction sink term in the momentum equations. This sink term was computed by averaging the turbines' thrust and structural drag forces over the $4 \mathrm{~km}^{2}$ area covered by the proposed array (Plew and Stevens, 2013). Further details about this numerical approach are available in Guillou and Thiébot (2016). The investigation considered horizontal-axis turbines with a blade diameter of $18.6 \mathrm{~m}$ and maximum power output of $1 \mathrm{MW}$ (Plew and Stevens, 2013; Guillou and Thiébot, 2016). Finally, simulations integrated five tidal farm configurations varying in the number of turbines: $10,50,100,150$, and 207 devices. The number of 207 turbines was obtained by retaining a density of 50 machines per $\mathrm{km}^{2}$ over the area identified for the implementation of tidal stream arrays in the Fromveur Strait (Thiébot et al., 2015).

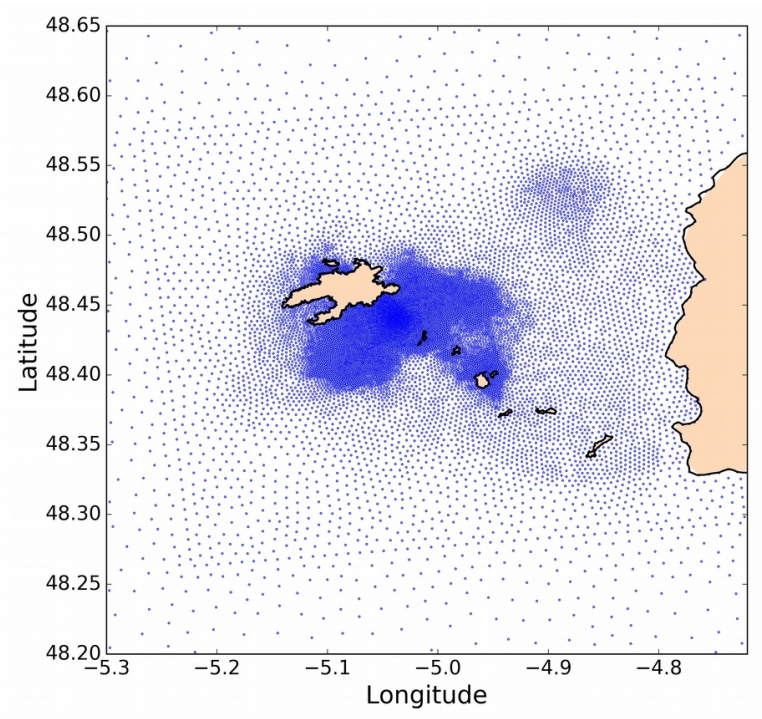

Figure 3. Spatial distribution of computational nodes around the Ushant-Molène archipelago. This distribution displays the initial particle positions.

\section{Results and Discussion}

\subsection{Evaluation of Model Predictions}

Attention was first directed to the evaluation of model's ability to reproduce tidal harmonic components. This was then followed by a comparison of predicted currents against observed currents.

Predicted amplitudes and phases of the $\mathrm{M}_{2}$ and $\mathrm{M}_{4}$ harmonic components were computed with a simple Fourier analyses of predicted sea-surface elevations. The results were compared to values derived from tidal-gauge observations at four locations in western Brittany, corresponding to stations (i) $\mathrm{S} 1$ in offshore waters $\left(\lambda=6.033^{\circ} \mathrm{W}, \varphi=47.383^{\circ} \mathrm{N}\right)$, (ii) $\mathrm{S} 2$ near Ushant island $\left(\lambda=5.100^{\circ} \mathrm{W}, \varphi=48.450^{\circ} \mathrm{N}\right.$ ), (iii) $\mathrm{S} 3$ in the harbor of Brest $\left(\lambda=4.495^{\circ} \mathrm{W}, \varphi=48.383^{\circ} \mathrm{N}\right)$, and (iv) $\mathrm{S} 4$ in the harbor of 
Roscoff $\left(\lambda=3.967^{\circ} \mathrm{W}, \varphi=48.717^{\circ} \mathrm{N}\right)$ (Fig. 1a, Tables 1 and $2)$. The observations were extracted from the compilations established by Sinha and Pingree (1997) and Pouvreau (2008). The numerical results reproduced the amplitudes and phases of the harmonic components, and the northwards increase of the $\mathrm{M}_{2}$ amplitude with differences restricted to $1 \%$. Greater differences were obtained for $\mathrm{M}_{4}$ at point S4. These results were, however, consistent with the numerical estimations of Sinha and Pingree (1997), both models integrating lower spatial resolution around the islands and shoals of north-eastern Brittany. Finally, the predicted spatial distributions of the amplitudes and phases of $\mathrm{M}_{2}$ and $\mathrm{M}_{4}$ were consistent with maps published by Sinha and Pingree (1997) and Pineau-Guillou (2013) at the scale of the European shelf seas. These comparisons confirm the model's ability to assess tide-induced vertical variations of the water surface within the area of interest.

Table 1. Observed and predicted amplitudes $A$ and phases $G$ (relative to Greenwich) for $M_{2}$ harmonic constituent at four locations in western Brittany.

\begin{tabular}{|c|c|c|c|c|}
\hline \multirow{2}{*}{$\begin{array}{c}\text { Station } \\
\text { number }\end{array}$} & \multicolumn{2}{|c|}{ Observed } & \multicolumn{2}{c|}{ Modelled } \\
\cline { 2 - 5 } & A (m) & G (deg.) & A (m) & G (deg.) \\
\hline S1 (offshore) & 1.36 & 99.7 & 1.35 & 90.9 \\
\hline S2 (Ushant) & 2.07 & 111.0 & 2.09 & 99.9 \\
\hline S3 (Brest) & 2.05 & - & 2.06 & - \\
\hline S4 (Roscoff) & 2.70 & 142.8 & 2.69 & 133.1 \\
\hline
\end{tabular}

Table 2. Observed and predicted amplitudes $A$ and phases $G$ (relative to Greenwich) for $M_{4}$ harmonic constituent at four locations in western Brittany.

\begin{tabular}{|c|c|c|c|c|}
\hline \multirow{2}{*}{$\begin{array}{c}\text { Station } \\
\text { number }\end{array}$} & \multicolumn{2}{|c|}{ Observed } & \multicolumn{2}{c|}{ Modelled } \\
\cline { 2 - 5 } & $\mathbf{A}(\mathbf{m})$ & G (deg.) & $\mathbf{A ~ ( m )}$ & G (deg.) \\
\hline S1 (offshore) & $1.2 \times 10^{-2}$ & 296.5 & $1.2 \times 10^{-2}$ & 290.3 \\
\hline S2 (Ushant) & - & - & - & - \\
\hline S3 (Brest) & $5.4 \times 10^{-2}$ & - & $6.8 \times 10^{-2}$ & - \\
\hline S4 (Roscoff) & $5.4 \times 10^{-2}$ & 143.4 & $9.1 \times 10^{-2}$ & 120.0 \\
\hline
\end{tabular}

Evaluation of model's performances was completed by a comparison of predictions with measurements of current amplitude and direction, performed by the French navy SHOM, at two locations, in the Fromveur Strait (point C1, $\lambda=5.036^{\circ} \mathrm{W}, \varphi=48.449^{\circ} \mathrm{N}$ ) and north of Molène island (point $\mathrm{C} 2, \lambda=4.945^{\circ} \mathrm{W}, \varphi=48.423^{\circ} \mathrm{N}$ ) (Figs. 1b, 4, and 5). Measurements periods covered spring to neap tidal conditions between (i) 19 March and 2 April 1993 at point $\mathrm{C} 1$ and (ii) 14 May and 11 June 1993 at point C2.
Assuming vertical logarithmic velocity profiles, the comparison was conducted $10 \mathrm{~m}$ above the bed, matching the operating height of horizontal-axis turbines in the strait (Guillou et al., 2016). The agreement between predictions and observations was particularly noticeable in the Fromveur Strait. Numerical results approached the evolution of current amplitude seen in the observations, with a mean relative difference of $0.06 \mathrm{~m} \mathrm{~s}^{-1}$, and Pearson's correlation coefficient of 0.96 . Greater differences were seen to the north of Molène, a region characterised by complex hydrodynamics recirculations, impacted by shoals and islands. The numerical results reproduced the pronounced observed asymmetry of spring tidal currents with (i) strong and short north-eastern components and (ii) reduced, long-lasting south-western velocities. In both cases, the model simulated the abrupt changes observed between south-west and north-east directions.
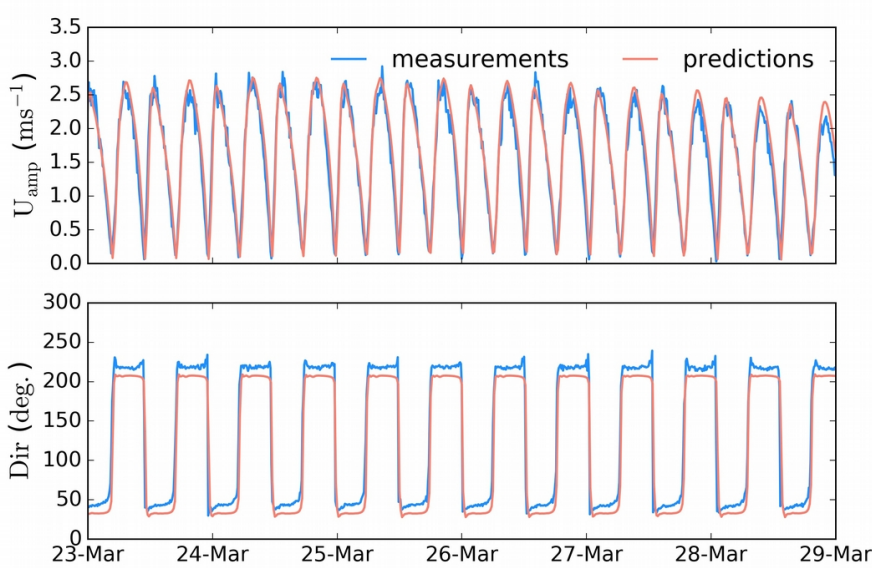

Figure 4. Measured and computed time series of the amplitude and direction (anticlockwise convention from the East) of the current, $10 \mathrm{~m}$ above the bed, at point $\mathrm{C1}$ (Fig. 1) in March 1993.

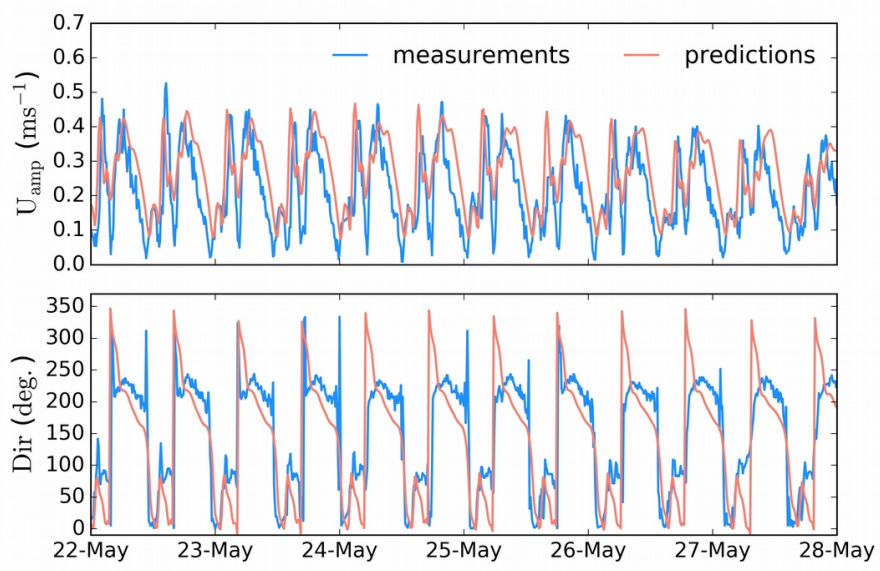

Figure 5. Measured and computed time series of the amplitude and direction (anticlockwise convention from the East) of the current, $10 \mathrm{~m}$ above the bed, at point $\mathrm{C} 2$ (Fig. 1) in May-June 1993. 


\subsection{Lagrangian Circulation Pathways}

In the Fromveur Strait, the predicted LRC exhibited a central divergence area between (i) a prominent northeastern pathway with residual currents up to $0.45 \mathrm{~m} \mathrm{~s}^{-1}$, and (ii) a southward circulation with Lagrangian currents restricted to $0.20 \mathrm{~m} \mathrm{~s}^{-1}$ (Fig. 6). This Lagrangian pattern was partly associated with the asymmetry of tidal currents in the strait, characterised by (i) a north-eastern flooddominated sector in the north, and (ii) a south-western ebbdominated region in the south (Guillou and Thiébot, 2016; Fig. 7). As revealed by a series of numerical investigations (Neill et al., 2014; Guillou and Chapalain, 2017; Guillou et al., 2018), such asymmetry is typical of tidal strait dynamics and arises from the phase relationship between $\mathrm{M}_{2}$ and $\mathrm{M}_{4}$. The central divergence area of tidal straits is thus primarily targeted for the development of tidal farm projects as it is characterised by reduced current asymmetry allowing thus balanced energy production between flood and ebb.

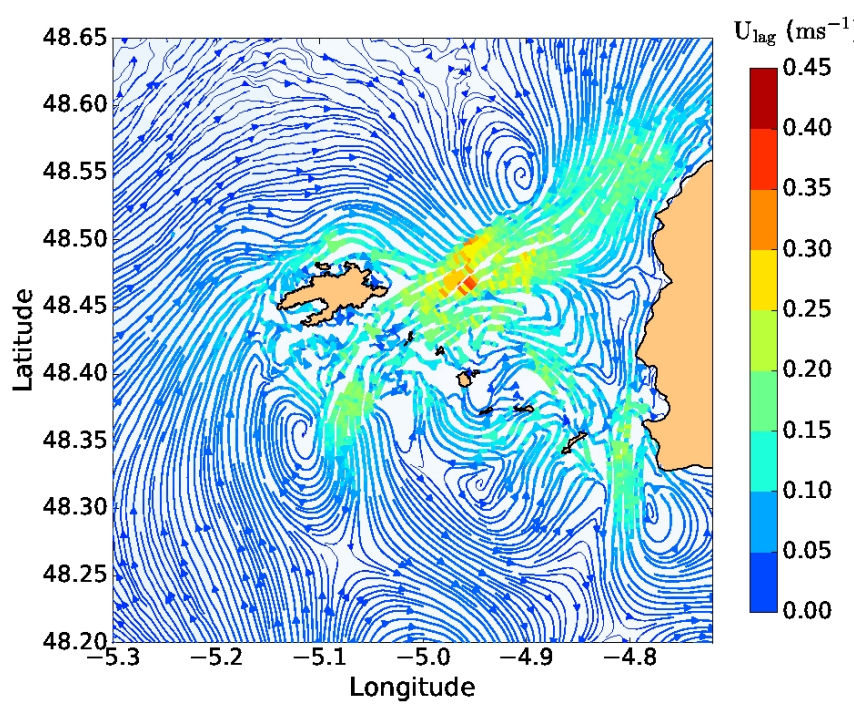

Figure 6. Streamlines from tidal residual Lagrangian currents without effects of stream power extraction.

Away from the strait, computed streamlines were consistent with the regional investigation conducted, in western Brittany, by Salomon et al. (1988) and based on the Lagrangian barycentric method. The residual currents thus exhibited a prominent northward pathway, which deflects towards the east around Ushant and connects to the circulation emerging from the Fromveur Strait.

Both upstream and downstream the strait, prominent cyclonic and anti-cyclonic recirculations, with diameters of around $8 \mathrm{~km}$, were seen. The LRC placed these eddies to the south and north-east of Ushant, respectively. The location of the northern eddy differed, however, from previous regional investigations conducted at the scale of western Brittany. Salomon et al. (1988) located this Lagrangian structure to the north of Ushant island by applying the Lagrangian barycentric method to regional tidal predictions. Muller et al. (2009) positioned it further
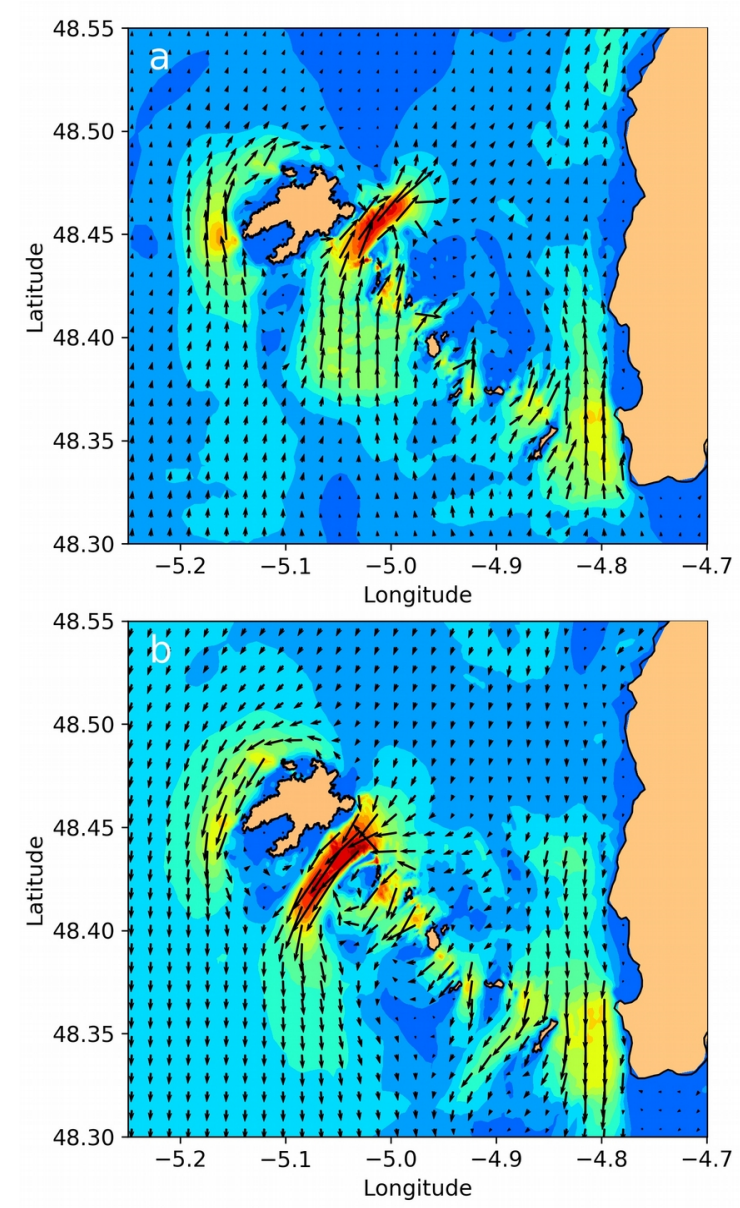

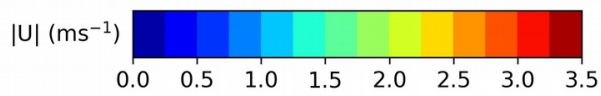

Figure 7. Depth-averaged currents without tidal stream array at times of (a) flood and (b) ebb peaks of a $\mathrm{M}_{2}$ tidal cycle in the Fromveur Strait.

west by relying on High-Frequency Radar (HFR) observations of the surface circulation in calm weather conditions. Nevertheless, the eddy, identified to the northeast of Ushant island, was closely correlated with the Bank of the Four, which confirms its position (Figs. 1 and 6). It was thus centred at the edge of the corner formed by the bank while extending to its southern and eastern limits. Following Neill and Scourse (2009) and Guillou and Chapalain (2011), a possible relationship may exist between this prominent sandbank and the tide-induced Lagrangian structure.

Further simulations showed that this residual eddy resulted from recirculations that appeared on the western edge of the flow emerging from the Fromveur Strait (Fig. 8). The residual Lagrangian structure was thus still present if the sandbank was removed from the bathymetry. It seems therefore that a refined spatial resolution is required to resolve the residual circulation emerging from the strait and 


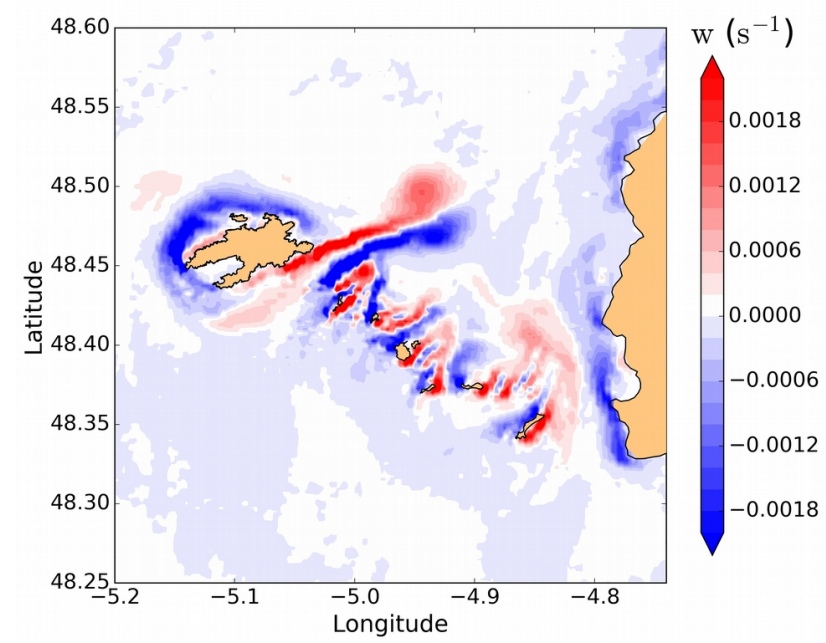

Figure 8. Vorticity of depth-averaged tidal currents during the flood period in the Fromveur Strait.

the associated recirculations. Previous studies in this area (Salomon et al., 1988; Muller et al., 2009) were conducted at spatial resolutions between $650 \mathrm{~m}$ and $1.5 \mathrm{~km}$, whilst the numerical model adopted here used a mesh size of $50 \mathrm{~m}$ in the strait. This explains the differences in the reported LRC around the Ushant-Molène archipelago.

\subsection{Particle Trajectories}

The investigation was completed with an analysis of float trajectories as validation of the Lagrangian barycentric method, and confirmation of the major features of the computed LRC. The initial particle positions were selected at six locations of interest in and around the Ushant-Molène archipelago, including the positions of surrounding sandbanks (Fig. 1). Predictions exhibited the dispersion of particle pathways with respect to the initial time of release during the tidal cycle (Fig. 9). Drifters released in the south-western part of the Fromveur Strait may thus (i) flow towards the English Channel following the prominent north-eastern circulation, (ii) flow around the western side of Ushant, another prominent pathway, or (iii) be driven towards the southern boundary (Fig. 9-b). The computed LRC (Fig. 6) was, however, consistent with these trajectories, reproducing the pathways' variability. Particle trajectories confirmed, in particular, (i) the asymmetry of residual currents in the strait and (ii) surrounding recirculations. The initial release in the Four Channel displayed the cyclonic recirculation identified above the Bank of the Four (Fig. 9-c). Finally, the area of interest was characterised by short residence times. Whereas localised trapping areas may be identified in the nearshore waters of the Molène archipelago, particles released in the vicinity of the Fromveur Strait were characterised by short residence times, being evacuated from the area of interest, on average, in less than three days.
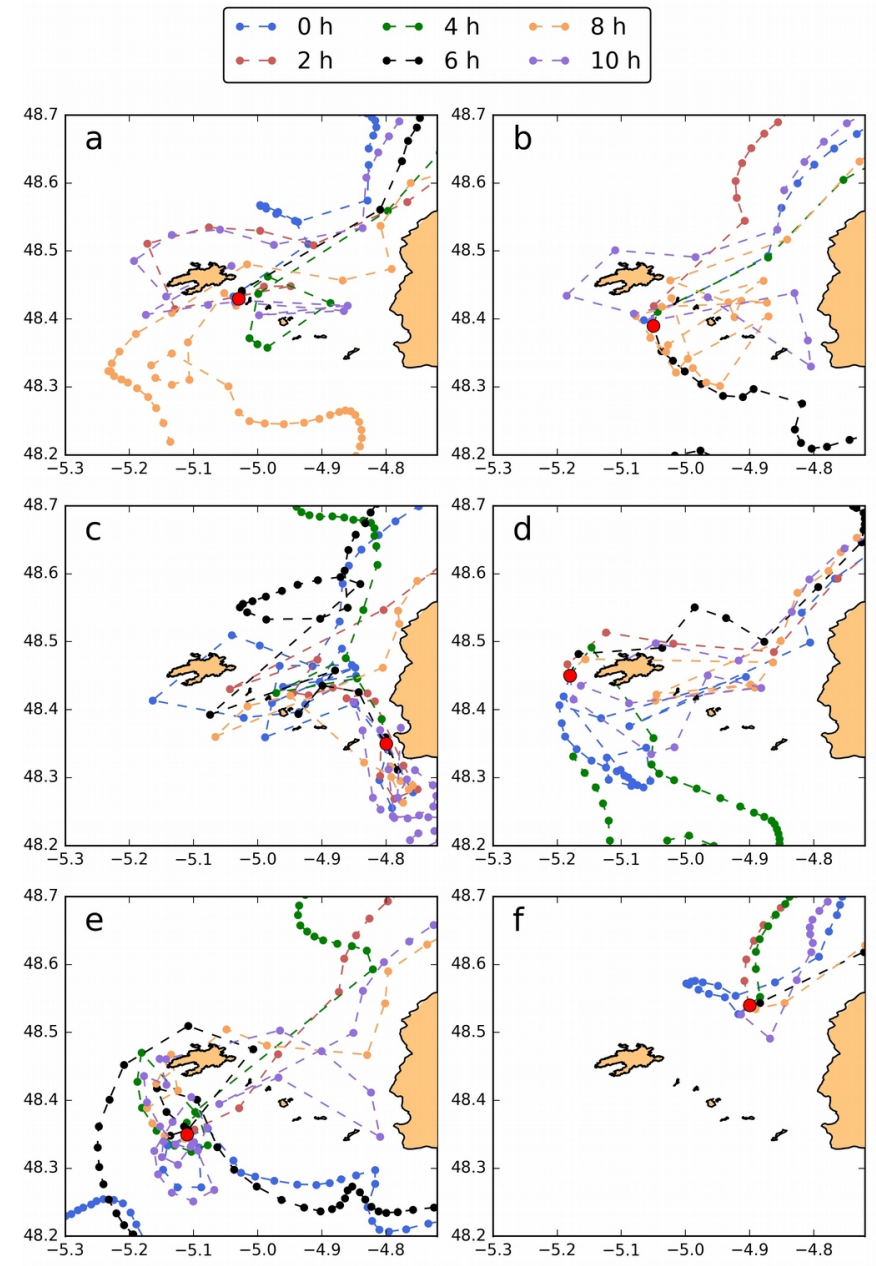

Figure 9. Long-term trajectories resulting from the release of floats, with a time step of 2 hours, during a $M_{2}$ tidal cycle. The initial positions of floats are indicated with red circles. Particles positions are displayed every 12 hours to facilitate the interpretation of trajectories.

\subsection{Effects of Tidal Stream Power Extraction}

The extraction of tidal stream power impacted mainly (i) the amplitude and direction of the residual currents emerging from the Fromveur Strait and (ii) the locations of surroundings eddies (Figs. 10 and 11). The southward Lagrangian pathway was thus found to deviate westwards, modifying the anti-cyclonic recirculation identified in the vicinity of the Bank of Ushant. The north-eastern Lagrangian pathway, emerging from the strait, was characterised by a reduced amplitude, which displaced south-westwards the location of the cyclonic eddy to the northeast of Ushant. For the extreme array configuration that incorporated 207 turbines, the positions of the southern and northern eddies were modified by 3 and $1.7 \mathrm{~km}$, respectively. These modifications may have possible implications on the evolutions of sandbanks. This may 


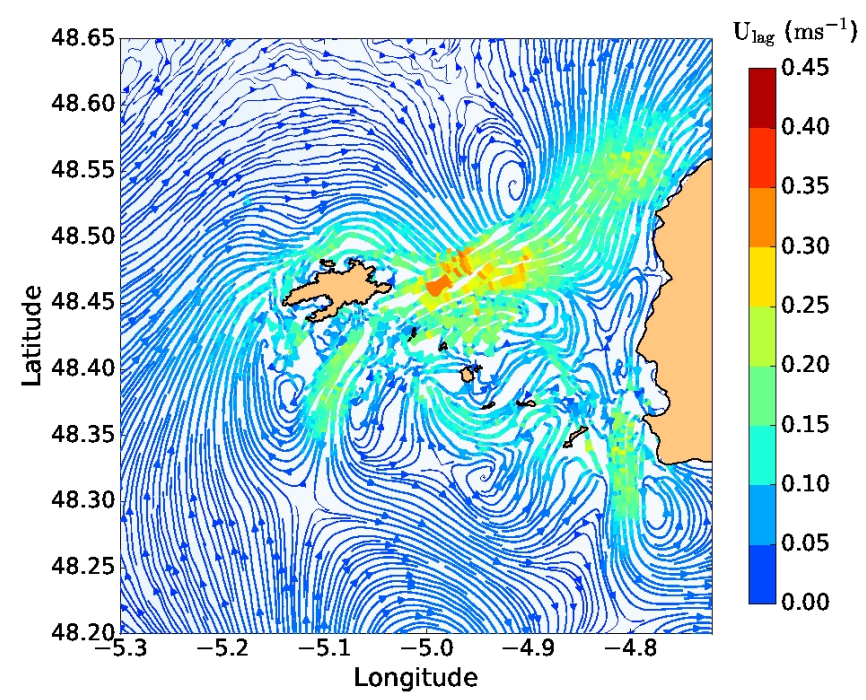

Figure 10. Streamlines from tidal residual Lagrangian currents with effects of stream power extraction from a series of 207 devices in the Fromveur Strait.

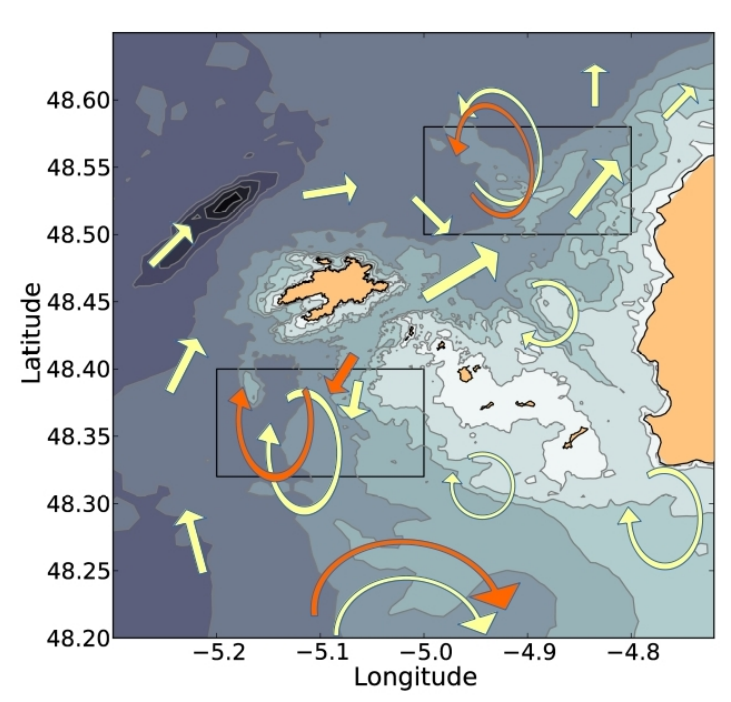

Depth (m)

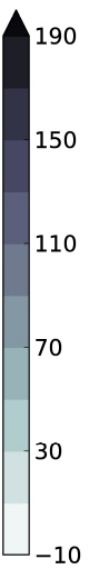

Figure 11. Interpretation of major features of residual Lagrangian currents patterns without (yellow lines) and with (orange lines) a tidal farm of 207 turbines in the Fromveur Strait. The spatial distribution of mean water depth is displayed in grey scale. The black lines delimit the areas displayed in Fig. 12.

impact mainly the Bank of the Four, whose location correlated strongly with the northern eddy (Section 3.2). As the southern eddy was closer to the strait than the northern eddy, changes induced by tidal stream power extraction were more noticeable for this recirculation. For the 50 device array configuration, the centre of the southern eddy moved by $820 \mathrm{~m}$ whilst the displacement of the northern recirculation was restricted to $220 \mathrm{~m}$. Furthermore, the induced modifications followed a non-linear evolution with respect to the number of turbines. The displacement of the eddy centres evolved in stages, as exhibited by the small differences seen between the 100 and 150 turbine configurations (Fig. 12).
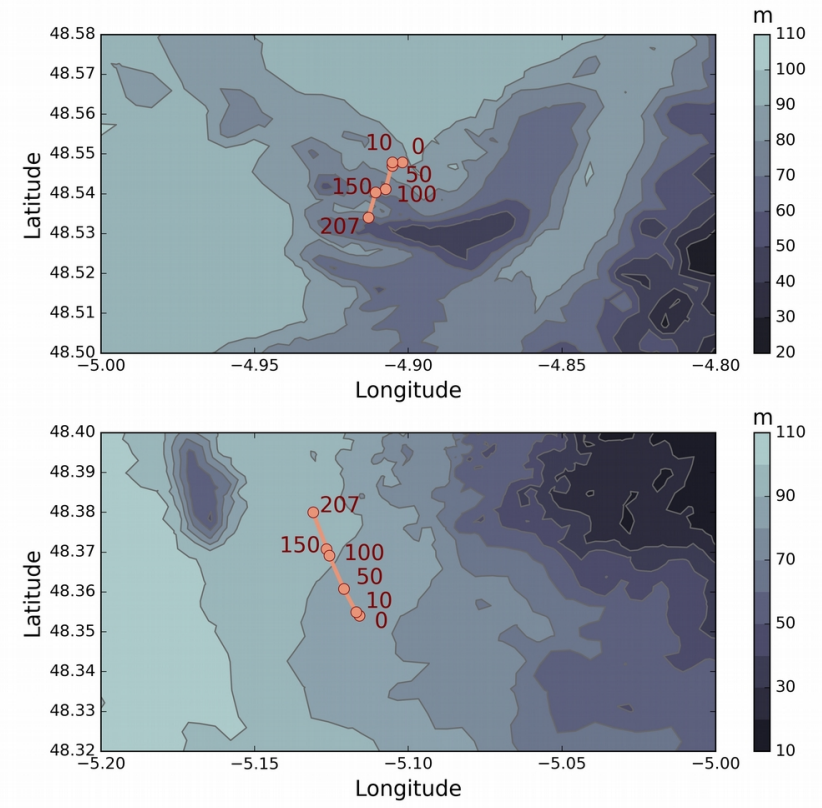

Figure 12. Positions of the centres of the (top) northern and (bottom) southern Lagrangian residual recirculations identified on both part of the Fromveur Strait without turbines and for a series of devices in the tidal farm.

\section{Conclusions}

An original approach, coupling the Lagrangian barycentric method with predictions from a high-resolution depthaveraged circulation model, was applied to the tidal stream energy site of the Fromveur Strait in western Brittany (France). The main outcomes of the present investigation are as follows:

1. Predicted streamlines refined the definition of the LRC in the Ushant-Molène archipelago exhibiting prominent transport pathways and recirculations liable to trap water particles. The strait was characterised by a strong asymmetry between (i) a prominent north-eastern pathway with residual currents up to $0.45 \mathrm{~m} \mathrm{~s}^{-1}$ and (ii) a southward circulation. Both upstream and downstream of the strait, the computed LRC identified cyclonic and anti-cyclonic recirculations.

2. A close correlation was exhibited between the north cyclonic eddy and the Bank of the Four. The investigation of current vorticity highlighted that this residual eddy was generated from recirculations on the western edge of the flow emerging from the strait. Refined spatial resolutions are thus required to reproduce this recirculation, which 
explains differences between this and previous regional investigations.

3. The extraction of tidal stream power modified the amplitude and direction of residual currents emerging from the strait, and the positions of the surrounding eddies. These recirculations moved closer to the tidal stream energy site as the number of turbines increased. For the extreme configurations that integrated 207 devices, the displacements of the eddy centres exceeded $1.5 \mathrm{~km}$, with possible implications for the evolution of surrounding sand banks.

The Lagrangian barycentric method provided a synthetic overview of water particle trajectories exhibiting the major patterns of the complex circulation at the tidalstream energy site of the Fromveur Strait. However, further in situ observations of drifters trajectories are required to refine the assessment of the particle-tracking method retained here. Three-dimensional numerical modelling may furthermore be conducted to include the influences of meteorological forcings, in particular the wind-driven circulation.

\section{Acknowledgments}

The authors warmly thank Jean-Michel Hervouet (EDF R\&D) for his support in applying the particle transport module of Telemac 2D. Simulations were performed with the HPC facilities DATARMOR of "Pôle de Calcul et de Données pour la Mer" (PCDM). The present paper is a contribution to the research program DIADEME ("Design et InterActions des Dispositifs d'extraction d'Energies Marines avec l'Environnement") of the Laboratory of Coastal Engineering and Environment (Cerema, http://www.cerema.fr).

\section{References}

Breton, M. and Salomon, J.C. 1995. "A 2D long-term advection-dispersion model for the Channel and southern North Sea. Part A: validation through comparison with artificial radionuclides". Journal of Marine Systems, 6(5-6), 495-514

EDF R\&D 2013, TELEMAC modelling system TELEMAC-3D software - release 6.2. Technical report, EDF.

Edwards, K., Hare, J., Werner, F. and Blanton, B. 2006. "Lagrangian circulation on the Southeast US Continental Shelf: Implications for larval dispersal and retention". Continental Shelf Research, 26, 1375-1394.

Egbert, G. and Erofeeva, S.Y. 2002. "Efficient inverse modeling of barotropic ocean tides". Journal of Atmospheric and Oceanic Technology, 19, 183-204.

Fairley, I., Masters, I. and Karunarathna, H. 2015. “The cumulative impact of tidal stream turbine arrays on sediment transport in the Pentland Firth". Renewable Energy, 80, 755-769.

Guillou, N. and Chapalain, G. 2010. "Numerical simulation of tide-induced transport of heterogeneous sediments in the English Channel". Continental Shelf Research, 30, 806-819.

Guillou, N. and Chapalain, G. 2011. "Effects of waves on the initiation of headland-associated sandbanks". Continental Shelf Research. 31, 1202-1213.

Guillou, N. and Chapalain, G. 2015. "Numerical modelling of nearshore wave energy resource in the Sea of Iroise". Renewable Energy, 83, 942-953.

Guillou, N. and Thiébot, J. 2016. "The impact of seabed rock roughness on tidal stream power extraction". Energy, 112, 762-773.

Guillou, N., Chapalain, G. and Neill, S.P. 2016. "The influence of waves on the tidal kinetic energy resource at a tidal stream energy site". Applied Energy, 180, $402-415$.

Guillou, N. 2017. "Modelling effects of tidal currents on waves at a tidal stream energy site". Renewable Energy, 114, 180-190.

Guillou, N. and Chapalain, G. 2017. “Tidal Turbines' Layout in a Stream with Asymmetry and Misalignment". Energies, 10, 1892.

Guillou, N., Neill, S.P. and Robins, P.E. 2018. "Characterising the tidal stream power resource around France using a high-resolution harmonic database", Renewable Energy, 123, 706-718.

Hervouet, J.M. 2007. Hydrodynamics of free surface flows, modelling with the finite element method. Cambridge: Cambridge University Press.

Joly, A., Goeury, C. and Hervouet, J.M. 2014. Adding a particle transport module to Telemac-2D with applications to algae blooms and oil spills. Technical report, EDF R\&D.

Muller, H., Blanke, B., Dumas, F., Lekien, F. and Mariette V. 2009. "Estimating the Lagrangian residual circulation in the Iroise Sea". Journal of Marine Systems, 78, S17-36.

Neill, S.P., Jordan, J.R. and Couch, S.J. 2012. "Impact of tidal energy convertor (TEC) arrays on the dynamics of headland sand banks". Renewable Energy, 37, 387-397.

Neill, S.P., Hashemi, R. and Lewis, M. 2014. "The role of tidal asymmetry in characterizing the tidal energy resource of Orkney". Renewable Energy, 68, 337-350.

Neill, S.P. and Scourse, J.D. 2009. "The formation of headland/island sandbanks". Continental Shelf Research, 29, 2167-2177. 
Orbi, A. and Salomon, J.C. 1988. "Dynamique de marée dans le Golfe Normand-Breton". Oceanologica Acta, 11(1), 55-64.

Pingree, R. and Maddock, L., 1978. "The $\mathrm{M}_{4}$ tide in the English Channel derived from a non-linear numerical model of the $\mathrm{M}_{2}$ tide". Deep-Sea Research, 25, 53-63.

Pineau-Guillou, L. 2013. PREVIMER Validation des atlas de composantes harmoniques de hauteurs et courants de marée. Technical report, Ifremer.

Plew, D. and Stevens, C. 2013. "Numerical modelling of the effects of turbines on currents in a tidal channel Tory Channel, New Zealand". Renewable Energy, 57, 269-282.

Pouvreau N. 2008. Trois cents ans de mesures marégraphiques en France: outils, méthodes et tendances des composantes du niveau de la mer au port de Brest. Ph.D. thesis. Université de La Rochelle.

Salomon, J.C., Guéguéniat, P., Orbi, A. and Baron, Y. 1988. "A Lagrangian model for long-term tidally induced transport and mixing. Verification by artificial radionuclide concentrations". In: Guary, J, Guéguéniat, P., R.P. editors. Radionuclides: a tool for oceanography. London, New York: Elsevier Applied Science Publishers, pp. 384-394.

Salomon, J.C. and Breton, M. 1993. "An atlas of long-term currents in the Channel". Oceanologica Acta, 16(5-6), 439-448.

Sanderson, B. and Redden, A. 2015. "Perspective on the risk that sediment-laden ice poses to in-stream tidal turbines in Minas Passage, Bay of Fundy". International Journal of Marine Energy, 10, 52-69.

Shapiro, G.I. 2011. "Effect of tidal stream power generation on the region-wide circulation in a shallow sea". Ocean Science, 7, 165-174.

Sinha, B. and Pingree, R.D. 1997. "The principal lunar semidiurnal tide and its harmonics: baseline solutions for $\mathrm{M}_{2}$ and $\mathrm{M}_{4}$ constituents on the North-West European Continental Shelf'. Continental Shelf Research, 1(11), 1321-1365.

Thiébot, J., Bailly du Bois, P. and Guillou, S. 2015. "Numerical modeling of the effect of tidal stream turbines on the hydrodynamics and the sediment transport - Application to the Alderney Race (Raz Blanchard), France”. Renewable Energy, 75, 356-365.

Zimmermann, J.T.F. 1979. "On the Euler-Lagrangian transformation and the Stokes drift in the presence of oscillatory and residual currents". Deep-Sea Research, 26 A, 505-520. 